\title{
Monosodium urate crystals reduce osteocyte viability and indirectly promote a shift in osteocyte function towards a proinflammatory and proresorptive state
}

Ashika Chhana ${ }^{1}$, Bregina Pool ${ }^{1}$, Karen E. Callon ${ }^{1}$, Mei Lin Tay ${ }^{1}$, David Musson', Dorit Naot ${ }^{1}$, Geraldine McCarthy², Susan McGlashan ${ }^{3}$, Jillian Cornish ${ }^{1}$ and Nicola Dalbeth ${ }^{1,4^{*}}$

\begin{abstract}
Background: Bone erosion is a frequent complication of gout and is strongly associated with tophi, which are lesions comprising inflammatory cells surrounding collections of monosodium urate (MSU) crystals. Osteocytes are important cellular mediators of bone remodeling. The aim of this study was to investigate the direct effects of MSU crystals and indirect effects of MSU crystal-induced inflammation on osteocytes.

Methods: For direct assays, MSU crystals were added to MLO-Y4 osteocyte cell line cultures or primary mouse osteocyte cultures. For indirect assays, the RAW264.7 macrophage cell line was cultured with or without MSU crystals, and conditioned medium from these cultures was added to MLO-Y4 cells. MLO-Y4 cell viability was assessed using alamarBlue ${ }^{\circledast}$ and LIVE/DEAD ${ }^{\oplus}$ assays, and MLO-Y4 cell gene expression and protein expression were assessed by real-time polymerase chain reaction (PCR) and enzyme-linked immunosorbent assay (ELISA), respectively. Histological analysis was used to examine the relationship between MSU crystals, inflammatory cells, and osteocytes in human joints affected by tophaceous gout.

Results: In direct assays, MSU crystals reduced MLO-Y4 cell and primary mouse osteocyte viability but did not alter MLO-Y4 cell gene expression. In contrast, conditioned medium from MSU crystal-stimulated RAW264.7 macrophages did not affect MLO-Y4 cell viability but significantly increased MLO-Y4 cell expression of osteocyte-related factors including E11, connexin 43, and RANKL, and inflammatory mediators such as interleukin (IL)-6, IL-11, tumor necrosis factor (TNF)- $a$ and cyclooxygenase-2 (COX-2). Inhibition of COX-2 in MLO-Y4 cells significantly reduced the indirect effects of MSU crystals. In histological analysis, $\mathrm{CD} 8^{+}$macrophages and MSU crystals were identified in close proximity to osteocytes within bone. COX-2 expression was also observed in tophaceous joint samples.

Conclusions: MSU crystals directly inhibit osteocyte viability and, through interactions with macrophages, indirectly promote a shift in osteocyte function that favors bone resorption and inflammation. These interactions may contribute to disordered bone remodeling in gout.
\end{abstract}

Keywords: Gout, Osteocyte, Inflammation, Urate, Bone erosion

\footnotetext{
* Correspondence: n.dalbeth@auckland.ac.nz

'Department of Medicine, Bone \& Joint Research Group, University of

Auckland, Auckland, New Zealand

${ }^{4}$ Department of Medicine, Faculty of Medical and Health Sciences, University

of Auckland, 85 Park Rd, Grafton, Auckland, New Zealand

Full list of author information is available at the end of the article
}

C The Author(s). 2018 Open Access This article is distributed under the terms of the Creative Commons Attribution 4.0 International License (http://creativecommons.org/licenses/by/4.0/), which permits unrestricted use, distribution, and reproduction in any medium, provided you give appropriate credit to the original author(s) and the source, provide a link to the Creative Commons license, and indicate if changes were made. The Creative Commons Public Domain Dedication waiver (http://creativecommons.org/publicdomain/zero/1.0/) applies to the data made available in this article, unless otherwise stated. 


\section{Background}

Bone erosion is a common complication of tophaceous gout [1]. Tophi are ordered structures containing inflammatory cells and tissue surrounding collections of monosodium urate (MSU) crystals [2]. Both MSU crystals and the soft tissue components of the tophus are strongly and independently associated with bone erosion in gout [3].

Joints affected by tophaceous gout show evidence of disordered bone remodeling, with increased osteoclastmediated bone resorption $[4,5]$ and impaired osteoblastmediated bone formation [6]. Osteocytes are the most abundant cell type found within bone and are important regulators of bone remodeling, controlling both bone resorption and bone formation [7, 8]. Embedded within the mineralized matrix, osteocytes communicate with each other and other cells on the bone surface through dendrites. Osteocytes are also a source of soluble factors that can target local and distant tissues [9]. We have previously reported that osteocyte-derived soluble factors mediate the relationship between tophus and erosion in gout [10], suggesting that osteocytes may contribute to the development of bone erosion in gout. The aim of this study was to investigate the direct effects of MSU crystals and indirect effects of MSU crystal-induced inflammation on osteocyte viability and function.

\section{Methods}

\section{Ethical approvals}

Human sample collection was approved by the Northern Regional Ethics Committee and all participants provided written informed consent. Protocols involving animals were approved by the University of Auckland Animal Ethics Committee. Use of human cadaveric tissue was in accordance with the New Zealand Human Tissue Act 2008.

\section{Cell culture}

MLO-Y4 cells (a kind gift from Professor Lynda Bonewald, Indiana University) were cultured in $\alpha$-minimum essential medium (MEM) containing L-glutamine and nucleosides (Gibco, Life Technologies, Thermo Fisher Scientific, Waltham, USA) and supplemented with $2.5 \%$ heat-inactivated fetal bovine serum (FBS; Gibco) and $2.5 \%$ heat-inactivated newborn calf serum (Hyclone, GE Healthcare Life Sciences, Logan, USA). The MLO-Y4 cell line is widely used for in-vitro studies of osteocytes; these cells have similar properties to primary osteocytes with high expression of osteocalcin and connexin 43. MLO-Y4 cells also have dendritic processes and can communicate via gap junctions, similar to primary osteocytes $[11,12]$.

Primary mouse osteocytes were isolated from the long bones of 6-week-old C57BL/6 male mice using a modified method of Stern et al. [13]. The long bones (femur, tibia, and humerus) were harvested, the epiphyses removed, and bone marrow flushed out with $\alpha$-MEM. Bones were then cut into small pieces and sequentially digested nine times using $300 \mathrm{U} / \mathrm{mL}$ collagenase (Sigma-Aldrich, St. Louis, USA; digests 1-3, 5, 7, and 9; 25 min per digest) and $5 \mathrm{mM}$ EDTA (Sigma-Aldrich; digests 4,6 , and $8 ; 40$ min per digest) at $37{ }^{\circ} \mathrm{C}$. Bone chips were washed with Hank's balanced salt solution (Gibco) between digests. Osteocyte-like cells were grown out from the digested bone chips onto collagen-coated surfaces with the same medium that was used for MLO-Y4 cells.

For all experiments, MLO-Y4 cells or primary mouse osteocytes were seeded in three-dimensional (3D) collagen gels in 24 -well plates $\left(1 \times 10^{4}\right.$ cells/50 $\mu \mathrm{L}$ gel; 1 gel/ well) as previously described [14]. Briefly, rat collagen type I (Corning Inc., Corning, USA) was neutralized with $1 \mathrm{M} \mathrm{NaOH}$ and diluted to a final concentration of $3 \mathrm{mg} / \mathrm{mL}$. Cells were seeded in $50 \mu \mathrm{L}$ collagen gels and allowed to set at $37^{\circ} \mathrm{C}$ for $1 \mathrm{~h}$ prior to the addition of $1 \mathrm{~mL}$ culture medium. Cells were cultured in the collagen gels for 4 days (MLO-Y4 cells) or $24 \mathrm{~h}$ (primary mouse osteocytes) before the media were replaced and experiments commenced.

The RAW264.7 macrophage cell line (ATCC, Manassas, USA) was maintained in Iscove's modified Dulbecco's medium supplemented with $1 \mathrm{mM}$ L-glutamine (both from Sigma-Aldrich) and 10\% FBS.

\section{MSU crystal synthesis}

Endotoxin-free MSU crystals were prepared by recrystallization from uric acid as previously described [15].

\section{Preparation of conditioned medium from RAW264.7 macrophages}

RAW264.7 cells were seeded in 24-well plates at $1 \times 10^{6}$ cells/well. The following day, the medium was changed to $\alpha$-MEM containing L-glutamine and nucleosides, supplemented with 2.5\% heat-inactivated FBS and 2.5\% heat-inactivated newborn calf serum, and $0.5 \mathrm{mg} / \mathrm{mL}$ MSU crystals were added for $24 \mathrm{~h}$. Conditioned medium was then harvested and filtered using a $0.2-\mu \mathrm{m}$ filter to remove any residual MSU crystals. The absence of MSU crystals was confirmed by polarizing light microscopy. Control conditioned medium from RAW264.7 macrophages alone (no added MSU crystals) was also prepared at the same time. There were up to 18 wells in each treatment group.

\section{alamarBlue $^{\circledR}$ assay for cell viability}

For direct assays, various concentrations of MSU crystals were added to MLO-Y4 cells or primary mouse osteocytes for $24 \mathrm{~h}$. Cells were then washed to remove MSU crystals and alamarBlue ${ }^{\bullet}$ reagent (Life Technologies) was 
added (5\% final concentration in a well) for $6 \mathrm{~h}$ at $37^{\circ} \mathrm{C}$. At the same time, $1 \mathrm{U} / \mathrm{mL}$ uricase (Sigma-Aldrich) was added to remove residual MSU crystals to prevent interference with the assay [6]. Cell viability was assessed both 24 and $48 \mathrm{~h}$ after the addition of MSU crystals by measuring fluorescence (excitation $540 \mathrm{~nm}$; emission $630 \mathrm{~nm}$ ) using a Synergy 2 multidetection microplate reader (BioTek Instruments Inc., Winooski, VT). In separate experiments, calcium pyrophosphate dihydrate (CPPD) crystals (Integrated Sciences, Sydney, Australia), basic calcium phosphate (BCP) crystals (synthesized as described previously [16]) and aluminum particulates (Sigma-Aldrich) were also added to MLO-Y4 cells for viability assays.

For indirect assays, 5\%, 20\%, or $40 \%$ control conditioned medium or MSU crystal-stimulated conditioned medium (from the RAW264.7 macrophage assays) was added to MLO-Y4 cells for $24 \mathrm{~h}$. Cells were then washed, and viability assessed using alamarBlue ${ }^{\circ}$ as above. There were up to six wells in each treatment group for all experiments.

\section{LIVE/DEAD ${ }^{\circledR}$ assay for cell viability}

MSU crystals ( 0.1 or $0.3 \mathrm{mg} / \mathrm{mL})$ were added to MLO-Y4 cells for $24 \mathrm{~h}$. Cells were washed, and crystals completely removed. Cells were then stained with calcein-AM (live cells) and ethidium homodimer-1 (dead cells) using the LIVE/DEAD ${ }^{\circ}$ Viability/Cytotoxicity Kit (Life Technologies), either 24 or $48 \mathrm{~h}$ after the addition of MSU crystals. Fluorescence microscopy was used to take 10 paired images of stained cells (live and dead) within three separate layers of the collagen gel (top, middle, and bottom). Image software (https://imagej.nih.gov/ij/) was used to count the number of living or dead cells in each gel layer and the percentage of dead cells was calculated.

\section{Gene and protein expression assays}

For direct assays, $0.1 \mathrm{mg} / \mathrm{mL}$ MSU crystals were added to MLO-Y4 cells for $0,1,6$, and $24 \mathrm{~h}$. For indirect assays, 40\% RAW264.7 conditioned medium (control or MSU crystal-stimulated) was added to MLO-Y4 cells for $0,1,6$, and $24 \mathrm{~h}$. MLO-Y4 cells were harvested for gene expression analysis, and MLO-Y4 cell supernatants and RAW264.7 macrophage conditioned medium preparations were harvested for secreted protein analysis. For each experiment, there were 6-12 wells in each treatment group.

\section{Quantitative real-time polymerase chain reaction (PCR)}

Purification of total cellular RNA, synthesis of cDNA, and real-time PCR was performed as previously described [14]. 18S rRNA endogenous control was used to correct for variations in cell numbers between samples.
The $\Delta \Delta \mathrm{Ct}$ method was used to calculate the relative levels of gene expression, using day 0 or control cell (MLO-Y4 cells alone) expression levels as a control.

\section{Protein quantification}

Protein levels of tumor necrosis factor (TNF)- $\alpha$, interleukin (IL)-6, IL-1 $\beta$, soluble receptor activator of nuclear factor kappa-B ligand (RANKL), and osteoprotegerin (OPG) in RAW264.7 macrophage conditioned medium preparations and MLO-Y4 supernatants was determined by enzyme-linked immunosorbent assay (ELISA) (R\&D Systems, Minneapolis, USA). Prostaglandin $\mathrm{E}_{2}\left(\mathrm{PGE}_{2}\right)$ was measured in conditioned media and supernatant samples as a measure of cyclooxygenase-2 (COX-2) enzyme activity using the $\mathrm{PGE}_{2}$ EIA Kit (Cayman Chemical, Ann Arbor, USA).

\section{TNF- $a$ and COX-2 inhibition experiments}

For TNF- $\alpha$ blocking experiments, $5 \mu \mathrm{g} / \mathrm{mL}$ TNF- $\alpha$ neutralizing antibody (monoclonal rat IgG1, clone MP6-XT22) or IgG1 isotype control (both from R\&D Systems) was added to MLO-Y4 cells for $1 \mathrm{~h}$ prior to the addition of RAW264.7 macrophage conditioned medium for $24 \mathrm{~h}$. The concentration of TNF- $\alpha$ neutralizing antibody was chosen based on optimization experiments whereby three different concentrations $(0.5,2.5$, and $5 \mu \mathrm{g} / \mathrm{mL})$ of neutralizing antibody was added to MLO-Y4 cells prior to the addition of $4 \mathrm{ng} /$ $\mathrm{mL}$ TNF- $\alpha$ for $24 \mathrm{~h}$. The addition of $5 \mu \mathrm{g} / \mathrm{mL}$ TNF- $\alpha$ neutralizing antibody suppressed TNF- $\alpha$-induced expression of COX-2, IL-11, and RANKL genes by MLO-Y4 cells (data not shown).

For COX-2 blocking experiments, $1 \mu \mathrm{M}$ COX-2-specific inhibitor (SC-236, Sigma-Aldrich) was added to MLO-Y4 cells for $1 \mathrm{~h}$ prior to the addition of RAW264.7 macrophage conditioned medium for $24 \mathrm{~h}$.

\section{Histology of joint samples affected by gout}

Human joint samples (two each from finger proximal and distal interphalangeal joints, and one each from the knee, mid-foot, and a big toe interphalangeal joint) were obtained from two patients with gout undergoing orthopedic surgery and three cadaveric donors with microscopically proven gout. Cadaveric samples were transferred to $70 \%$ ethanol immediately after collection and all samples were demineralized at room temperature in $10 \%$ formic acid for 1 week prior to paraffin embedding. Slides were prepared and stained with toluidine blue as previously described [17] or used for immunohistochemistry. The spatial relationship between osteocytes, macrophages, and MSU crystals in joint samples was examined using polarizing light microscopy. Immunohistochemistry was used to identify $\mathrm{CD} 8^{+}$macrophage cells and COX-2 expression. 


\section{Immunohistochemistry for $\mathrm{CD} 68$ and $\mathrm{COX}-2$}

Sections were dewaxed for $12 \mathrm{~min}$ in Safsolvent (Ajax Finechem Pty Ltd., Melbourne, Australia) and rehydrated through graded ethanol solutions for 5 min each. Once hydrated, sections were immersed in $0.5 \%$ pepsin for $14 \mathrm{~min}$ at $37{ }^{\circ} \mathrm{C}(\mathrm{CD} 68)$ or $\mathrm{pH} 9.0$ Dako Target Retrieval Solution (Produktionsvej, Denmark) for $20 \mathrm{~min}$ at $96{ }^{\circ} \mathrm{C}$ (COX-2). To block endogenous peroxidase activity, sections were incubated in Dual Endogenous Enzyme-Blocking Reagent (Dako, Produktionsvej, Denmark) for 20 min (CD68) or 3\% hydrogen peroxide in methanol for $15 \mathrm{~min}$ (COX-2). To block nonspecific binding, sections were incubated in $10 \%$ goat serum for $30 \mathrm{~min}$ (CD68) or 3\% bovine serum albumin (MP Biomedicals New Zealand, Auckland, New Zealand) for $30 \mathrm{~min}$ (COX-2). Sections were incubated with primary antibody (1:200 dilution of anti-human CD68 clone PG-M1, Dako; 1:100 dilution of anti-human COX-2, clone SP21, Thermo Fisher Scientific) at $4{ }^{\circ} \mathrm{C}$ overnight. After washing with phosphate-buffered saline (PBS), slides were incubated with the Dako Dual link system peroxidase secondary antibody for $30 \mathrm{~min}$ (CD68) or $2 \mathrm{~h}$ (COX-2). After further washing, the Impact DAB Substrate Kit (Vector Laboratories, Burlingame, CA) was used to detect staining according to the manufacturer's instructions. Slides were briefly counterstained with Hematoxylin QS counter stain (Vector Laboratories) and dehydrated through graded ethanol solutions and xylol. Slides were mounted with DPX (BDH, Poole, UK) and analyzed by light microscopy.

\section{Statistical analysis}

Data were analyzed using SAS Software (SAS Institute, Cary, USA) and GraphPad Prism Software (v7, GraphPad Software, San Diego, USA). For all experiments, data were pooled from three to five biological repeats. Data were analyzed using one-way or two-way analysis of variance (ANOVA) with post-hoc Dunnett's or Sidak's multiple comparison tests in the case of more than two groups, or by two-tailed paired $t$ test in the case of two groups.

\section{Results}

MSU crystals directly reduce MLO-Y4 cell and primary mouse osteocyte cell viability over time

The higher concentrations of MSU crystals $(0.3-0.5 \mathrm{mg} /$ $\mathrm{mL}$ ) reduced the viability of MLO-Y4 cells and primary mouse osteocytes after $24 \mathrm{~h}$ as assessed by alamarBlue ${ }^{\circ}$ assays, with a further reduction in viability observed at the $48 \mathrm{~h}$ time point (Fig. 1a). The inhibitory effect was specific to MSU crystals, since soluble urate at the same concentrations (Fig. 1b) and other types of crystals (CPPD, BCP, aluminum) did not reduce MLO-Y4 cell viability (Fig. 1c). The effects on MLO-Y4 cell viability were not altered with different MSU crystal lengths (Additional file 1: Figure S1).
To assess whether MLO-Y4 cell death induced by MSU crystals was consistent throughout the 3D collagen gel, LIVE/DEAD ${ }^{\circ}$ assays were performed and MLO-Y4 cell death in the top, middle, and bottom layers of the collagen gel were determined. In these assays, significant MLO-Y4 cell death was observed in the top layer of the gel compared with the middle and bottom layers following culture with $0.3 \mathrm{mg} / \mathrm{mL}$ MSU crystals for $24 \mathrm{~h}$ or 48 h (Fig. 1d).

MSU crystals do not directly alter MLO-Y4 cell expression of bone-related or inflammatory genes

Real-time PCR was used to determine changes in gene expression in MLO-Y4 cells cultured with MSU crystals for 1,6 , and $24 \mathrm{~h}$. MSU crystals alone did not alter the expression of bone-related genes, including E11 (Pdpn), connexin 43 (Gja1), RANKL (Tnfsf11), or OPG (Tnfrs11b) (Fig. 2a), or inflammatory genes, including TNF- $\alpha$ (Tnfa), COX-2 (Ptgs2), IL-6 (Il6), and IL-11 (Il11) (Fig. 2b). IL-1 $\beta$ $(I l 1 b)$ was not expressed by MLO-Y4 cells.

\section{Conditioned medium from MSU crystal-stimulated RAW264.7 macrophages has no effect on MLO-Y4 cell viability}

To assess whether soluble factors released by macrophages in response to MSU crystals indirectly affect osteocyte viability, RAW264.7 cells were cultured with or without $0.5 \mathrm{mg} / \mathrm{mL}$ MSU crystals for $24 \mathrm{~h}$, and conditioned medium was harvested. The addition of increasing concentrations of control or MSU crystal-stimulated conditioned medium had no effect on MLO-Y4 cell viability as determined by the alamarBlue ${ }^{\curvearrowleft}$ assay after 24 and $48 \mathrm{~h}$ (Additional file 2: Figure S2).

\section{Conditioned medium from MSU crystal-stimulated RAW264.7 macrophages alters MLO-Y4 cell expression of bone-related factors and upregulates MLO-Y4 expression of inflammatory mediators}

The addition of $40 \%$ conditioned medium from MSU crystal-stimulated RAW264.7 macrophages to MLO-Y4 cell cultures led to an approximate two- to fourfold increase in expression of E11 and connexin 43 at the 6 and $24 \mathrm{~h}$ time points compared with control conditioned medium. RANKL expression was upregulated approximately sixfold at the 6 and $24 \mathrm{~h}$ time points, and OPG expression was reduced at the $6 \mathrm{~h}$ time point by approximately twofold (Fig. 3a).

The expression of inflammatory genes by MLO-Y4 cells was also significantly upregulated with the addition of MSU crystal-stimulated conditioned medium, including TNF- $\alpha$ ( 4-fold) after $1 \mathrm{~h}, \mathrm{COX}-2(\sim 11$-fold $)$ after 6 and $24 \mathrm{~h}$, IL- 6 after 6 and $24 \mathrm{~h}(\sim 1800$-fold and $\sim$ 700-fold, respectively), and IL-11 ( 200-fold) after 6 and 24 h (Fig. 3b). 

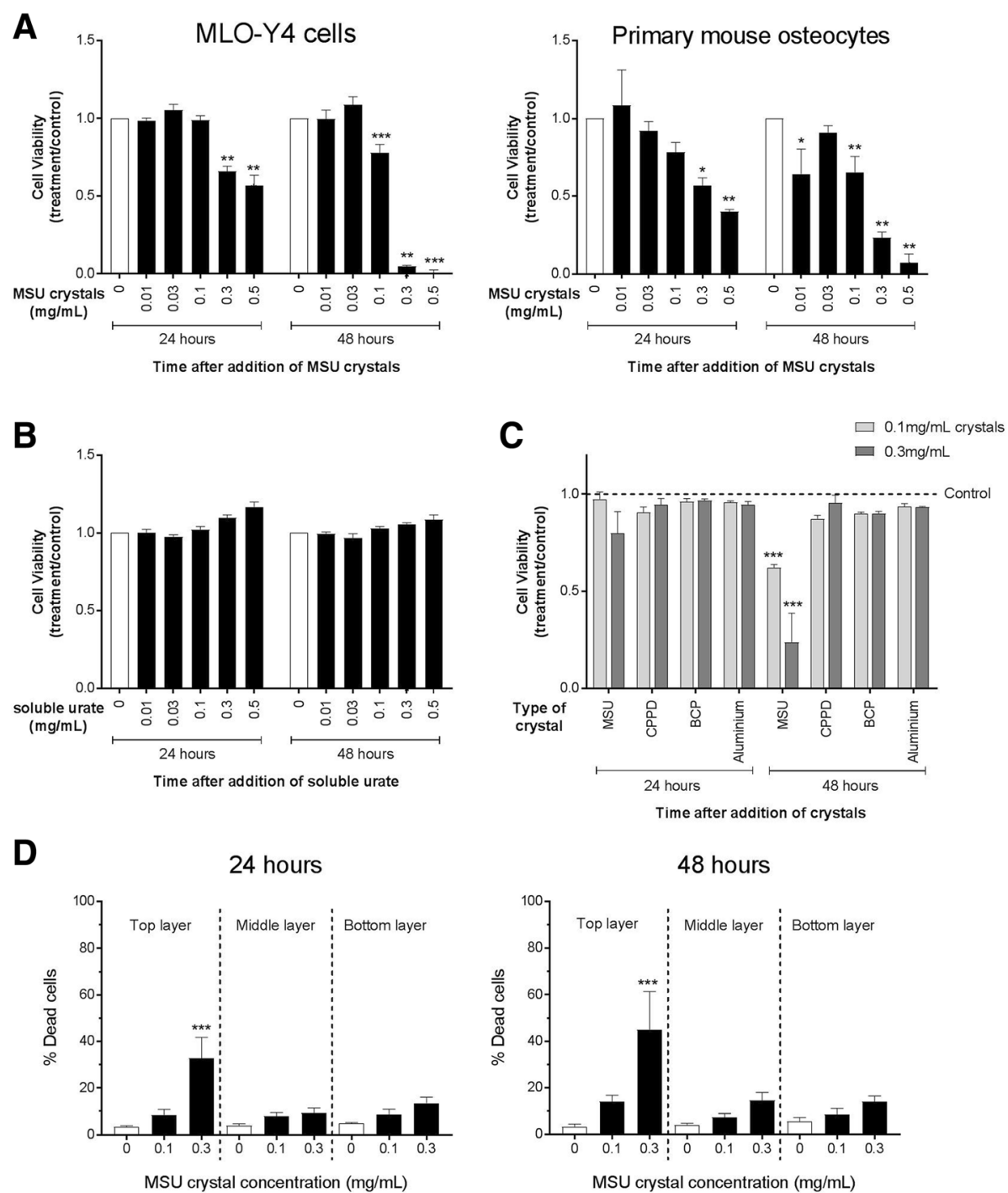

Fig. 1 The direct effects of MSU crystals on osteocyte viability. The alamarBlue ${ }^{\oplus}$ assay was used to determine the viability of a MLO-Y4 cells and primary mouse osteocytes cultured with monosodium urate (MSU) crystals for 24 h, b MLO-Y4 cells cultured with soluble urate for 24 h, and c MLO-Y4 cells cultured with different types of crystals for $24 \mathrm{~h}$. Viability was assessed 24 and $48 \mathrm{~h}$ after the addition of crystals or soluble urate. Data shown are pooled from three to four biological repeats and are presented as mean (SEM); by two-way ANOVA a $P_{\text {Interaction }}<0.0001$ for MLO-Y4 cells, $P_{\text {Interaction }}=0.026$ for primary mouse osteocytes, $\mathbf{b} P_{\text {Interaction }}=0.24$, and $\mathbf{c} P_{\text {Interaction }}=0.057$ at $24 \mathrm{~h}, P_{\text {Interaction }}<0.0001$ at 48 h; with post-hoc Dunnett's test ${ }^{*} p<0.05$, ${ }^{* *} p<0.01$, and ${ }^{* * *} p<0.001$ versus control (no crystals or soluble urate) at that time point. $\mathbf{d}^{*}$ The LIVE/DEAD ${ }^{\otimes}$ assay was used to determine the percentage of dead MLO-Y4 cells within three separate layers of the collagen gel following culture with MSU crystals for $24 \mathrm{~h}$ or $48 \mathrm{~h}$. Data shown are pooled from four biological repeats and are presented as mean (SEM); one-way ANOVA $p<0.0001$ at $24 \mathrm{~h}, p=0.004$ at $48 \mathrm{~h}$; with post-hoc Sidak's test ${ }^{* * *} p<0.001$ versus control (no MSU crystals) for each layer of the gel. BCP basic calcium phosphate, CPPD calcium pyrophosphate dehydrate

To assess changes at the protein level, MLO-Y4 cell supernatants were harvested and protein concentrations were measured in the MLO-Y4 cell supernatants and compared with RAW264.7 macrophage conditioned medium alone (before addition to MLO-Y4 cells). High levels of TNF- $\alpha, \mathrm{PGE}_{2}$, and IL-6 protein were secreted by MLO-Y4 cells in response to conditioned medium from RAW264.7 macrophages cultured with MSU crystals (Fig. 4a-c). OPG protein levels were unchanged
(Fig. 4d) and soluble RANKL was not detected in any conditioned media or supernatant samples.

The inflammatory response induced in MLO-Y4 cells by conditioned medium from MSU crystal-stimulated RAW264.7 macrophages is suppressed with inhibition of COX-2

The concentration of candidate inflammatory mediators and bone factors in conditioned medium collected from 

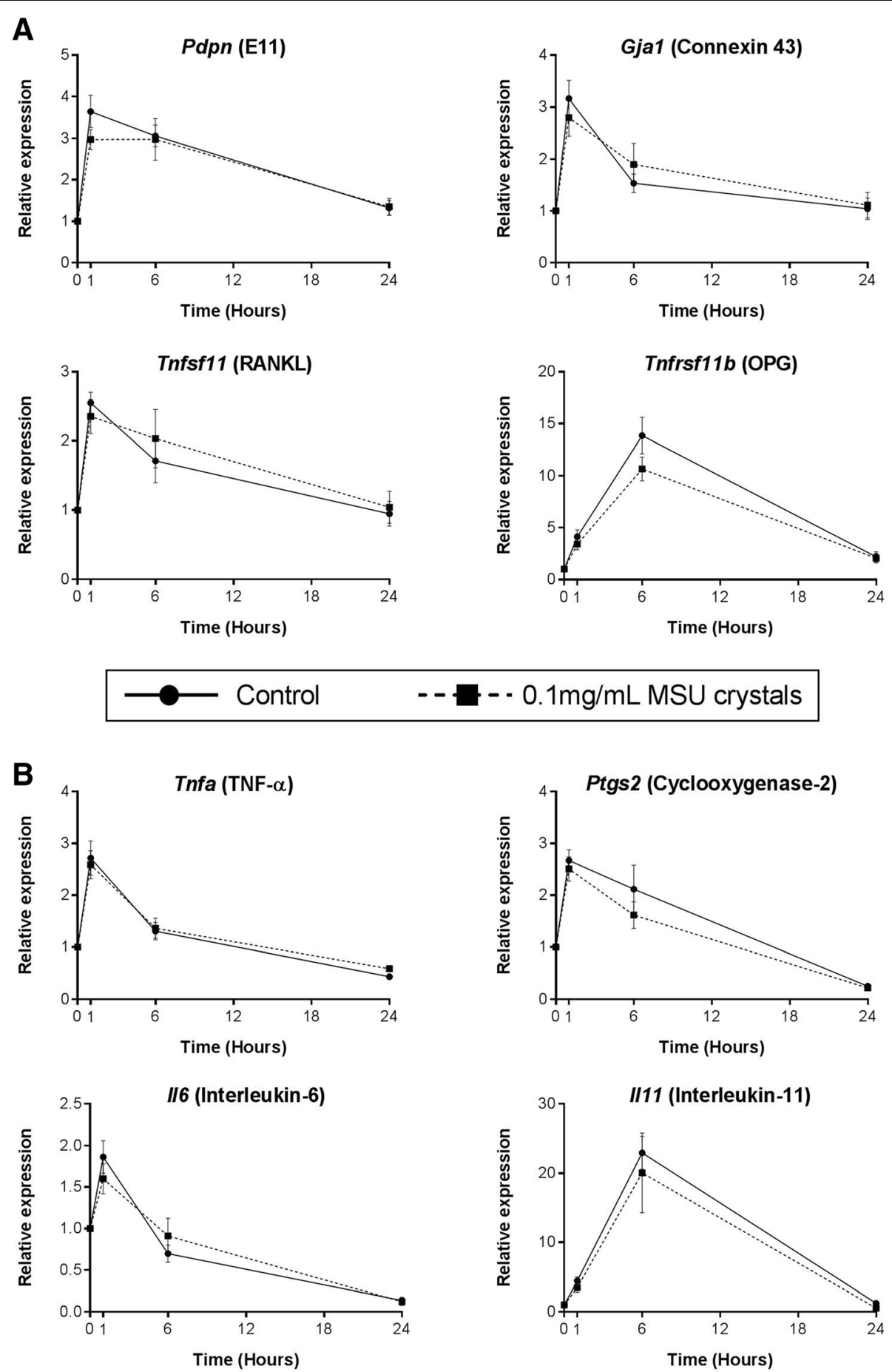

Fig. 2 Direct effects of MSU crystals on MLO-Y4 cell expression of bone-related or inflammatory genes. Real-time PCR was used to determine changes in the relative mRNA expression levels of $\mathbf{a}$ bone-related and $\mathbf{b}$ inflammatory genes in MLO-Y4 cells, following culture with $0.1 \mathrm{mg} / \mathrm{mL}$ monosodium urate (MSU) crystals for 0, 1, 6, and 24 h. Data shown are pooled from three biological repeats and are presented as mean (SEM); two-way ANOVA $P_{\text {Interaction }}>0.1$ for all genes. OPG osteoprotegerin, RANKL receptor activator of nuclear factor kappa-B ligand, TNF tumor necrosis factor

RAW264.7 macrophages was measured using ELISA. The addition of MSU crystals to RAW264.7 macrophages led to significantly increased secretion of TNF- $\alpha$ protein and $\mathrm{PGE}_{2}$ compared with control cells (without MSU crystals) (Additional file 3: Figure S3). There was no change in IL-1 $\beta$ or OPG release, and IL- 6 and soluble 

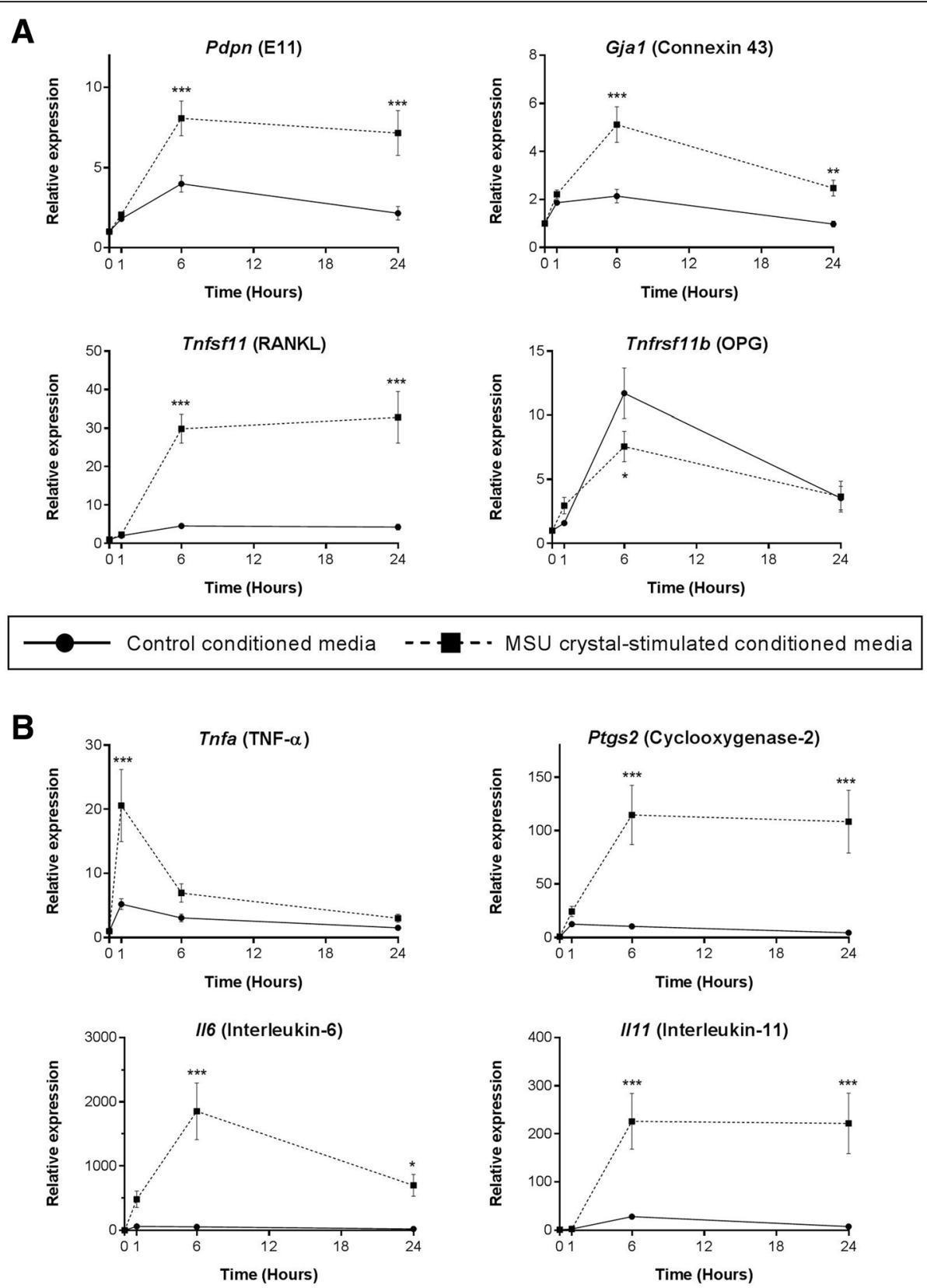

Fig. 3 Indirect effects of MSU crystal-stimulated RAW264.7 macrophage conditioned medium on MLO-Y4 cell gene expression. RAW264.7 macrophages were cultured with or without $0.5 \mathrm{mg} / \mathrm{mL}$ monosodium urate (MSU) crystals for $24 \mathrm{~h}$ for preparation of MSU crystal-stimulated conditioned medium and control conditioned medium, respectively. Conditioned medium preparations were added to MLO-Y4 cells (40\% final concentration in a well) for $0,1,6$, and 24 h. MLO-Y4 cells were harvested and real-time PCR was used to determine changes in the relative mRNA expression levels of $\mathbf{a}$ bone-related and $\mathbf{b}$ inflammatory genes. Data shown are pooled from three biological repeats and are presented as mean (SEM); two-way ANOVA $P_{\text {Interaction }}=0.007$ for Tnfrsf1 1b, $P_{\text {Interaction }}=0.0005$ for Tnfa, $P_{\text {Interaction }}<0.0001$ for all other genes; with post-hoc Sidak's test ${ }^{*} p<0.05,{ }^{* *} p<0.01$, and ${ }^{* * *} p<0.001$ versus control conditioned medium at that time point. OPG osteoprotegerin, RANKL receptor activator of nuclear factor kappa-B ligand, TNF tumor necrosis factor

RANKL protein were undetected in both control conditioned medium and MSU crystal-stimulated conditioned medium (Additional file 3: Figure S3).

The addition of TNF- $\alpha$ neutralizing antibody did not significantly change the induced expression of COX-2, IL-6, IL-11, and RANKL genes by MLO-Y4 cells following culture with MSU crystal-stimulated conditioned medium (Additional file 4: Figure S4). In contrast, addition of a COX-2 inhibitor to MLO-Y4 cell cultures prior to the addition of MSU crystal-stimulated conditioned medium led to a significant reduction in IL-6, IL-11, and RANKL gene expression (Fig. 5a), and $\mathrm{PGE}_{2}$ 

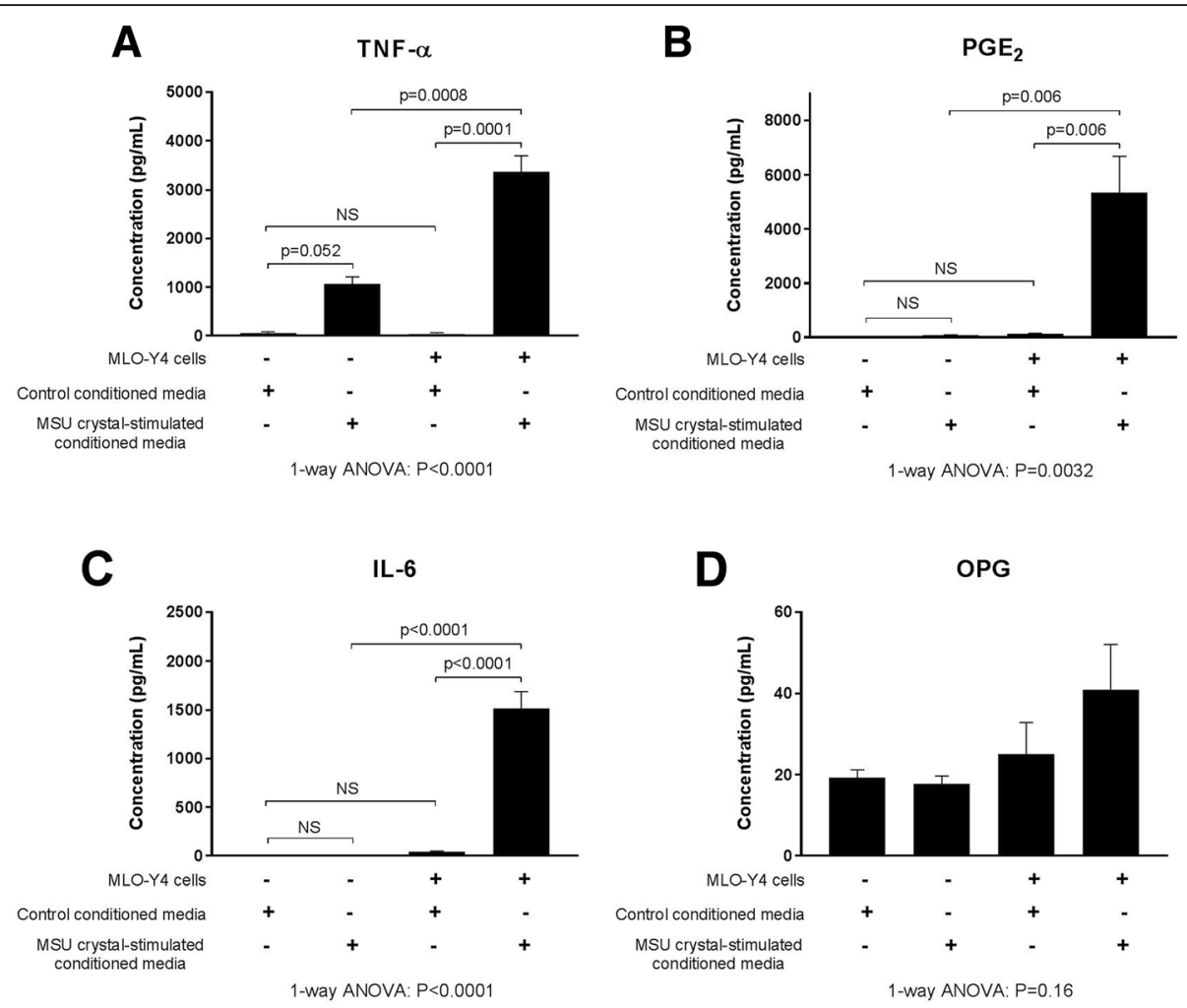

Fig. 4 Secretion of proinflammatory mediators by MLO-Y4 cells in response to MSU crystal-stimulated RAW264.7 macrophages. RAW264.7 macrophages were cultured with or without $0.5 \mathrm{mg} / \mathrm{mL}$ monosodium urate (MSU) crystals for $24 \mathrm{~h}$ for preparation of MSU crystal-stimulated conditioned medium and control conditioned medium, respectively. Conditioned medium preparations were added to MLO-Y4 cells (40\% final concentration in a well) for $24 \mathrm{~h}$ and supernatants harvested. The concentrations of a tumor necrosis factor (TNF)-a, b prostaglandin $\mathrm{E}_{2}$ (PGE $)$, $\mathbf{c}$ interleukin (IL)-6, and $\mathbf{d}$ osteoprotegerin (OPG) protein in the RAW264.7 macrophage conditioned medium samples (control and MSU crystalstimulated) and the MLO-Y4 cell supernatants were measured by ELISA. Data shown are pooled from three biological repeats and are presented as mean (SEM); one-way analysis of variance (ANOVA) with post-hoc Sidak's test between groups as indicated. NS no significant difference

and IL-6 protein expression (Fig. 5b). TNF- $\alpha$ gene expression was slightly increased following COX-2 inhibition (Fig. 5a); however, there was no difference at the protein level (Fig. 5b). MLO-Y4 cell gene expression of OPG and COX-2 was unchanged (Fig. 5a); however, $\mathrm{PGE}_{2}$ levels were significantly decreased with the addition of COX-2 inhibitor (Fig. 5b). Soluble RANKL protein was undetected in the MLO-Y4 cell supernatants.

\section{MSU crystals and macrophages are observed in close} proximity to bone, and COX-2 is also expressed in human joints affected by tophaceous gout

The clinical relevance of our in-vitro results was assessed by examining the relationship between MSU crystals, inflammatory cells, and bone in human joint tissue affected by gout. In joint samples from people with tophaceous gout, collections of MSU crystals were observed both immediately adjacent to the bone (direct contact) and also distant from the bone, separated from the bone surface by a rim of inflammatory tissue (Fig. 6a, b). Multiple $\mathrm{CD} 68^{+}$macrophages were identified within tophi adjacent to the bone (Fig. 6c). In addition, COX-2 expression was observed in both mononucleated and multinucleated cells within the corona zone of tophi and in cells close to the bone in joints affected by tophaceous gout (Fig. 6d).

\section{Discussion}

This study shows that MSU crystals have significant inhibitory effects on osteocyte viability, but no direct effect on osteocyte gene expression in vitro. In contrast, in conditioned media experiments, factors released by macrophages in response to MSU crystals have profound effects on the expression profile of osteocytes, with upregulated expression of inflammatory cytokines and mediators, and altered expression of factors involved in bone remodeling. The shift in osteocyte function towards a proinflammatory and proresorptive state is effectively suppressed with COX-2 inhibition.

Our in-vitro assays demonstrate that MSU crystals directly reduce the viability of osteocytes embedded within $3 \mathrm{D}$ collagen gels over time. Although the alamarBlue ${ }^{\bullet}$ results showed that direct cell-crystal contact was not necessarily required for this effect, the increased level of 


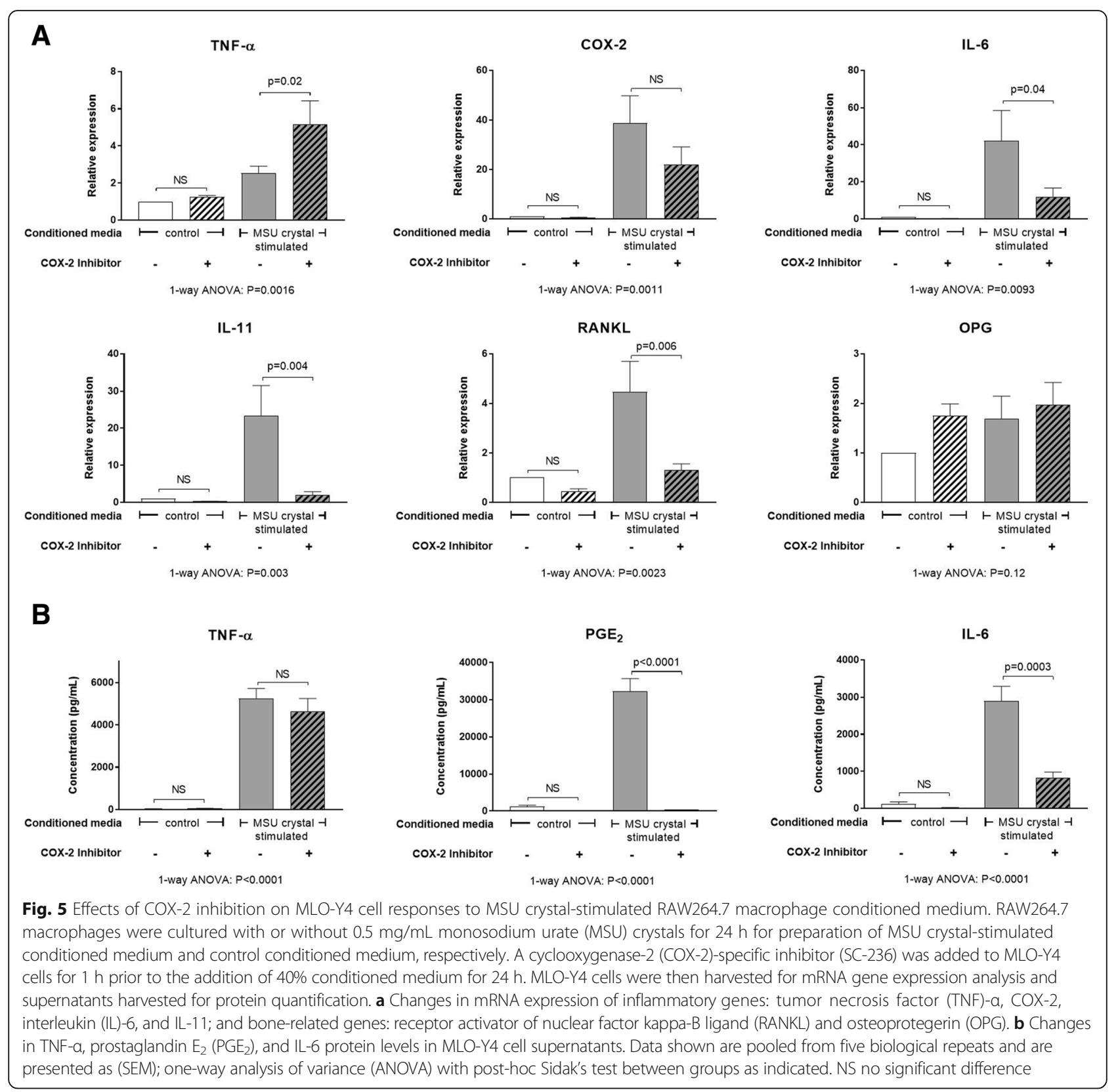

cell death observed in the top layer of the gel in the LIVE/DEAD ${ }^{\circ}$ assays suggests that direct cell-crystal contact may enhance MSU crystal-induced osteocyte death. Osteocyte cell death is associated with increased osteoclastogenesis and loss of bone [18], with dying osteocytes and their neighboring cells thought to send signals which recruit osteoclast precursors to areas of bone damage $[19,20]$. In patients with tophaceous gout, large numbers of osteoclasts are present at the bone-tophus interface at the site of bone erosion [4]. Increased osteocyte death in the presence of MSU crystals may further amplify osteoclast precursor cell recruitment, osteoclastogenesis, and bone resorption at these sites.
MSU crystals did not directly alter MLO-Y4 gene expression in our 3D in-vitro cell culture model and, while direct interaction of MSU crystals with cells in the deeper layers of the gels may have been limited, this model is more representative of osteocytes in vivo which are embedded within a 3D matrix. The histology analysis confirmed that, while MSU crystals are in direct contact with surface bone cells, there is often a rim of macrophages and inflammatory tissue observed between MSU crystals and osteocytes within the bone. Interactions between nearby MSU crystals and macrophages and the resulting inflammation may also influence osteocyte regulation of bone remodeling in joints affected by tophaceous 

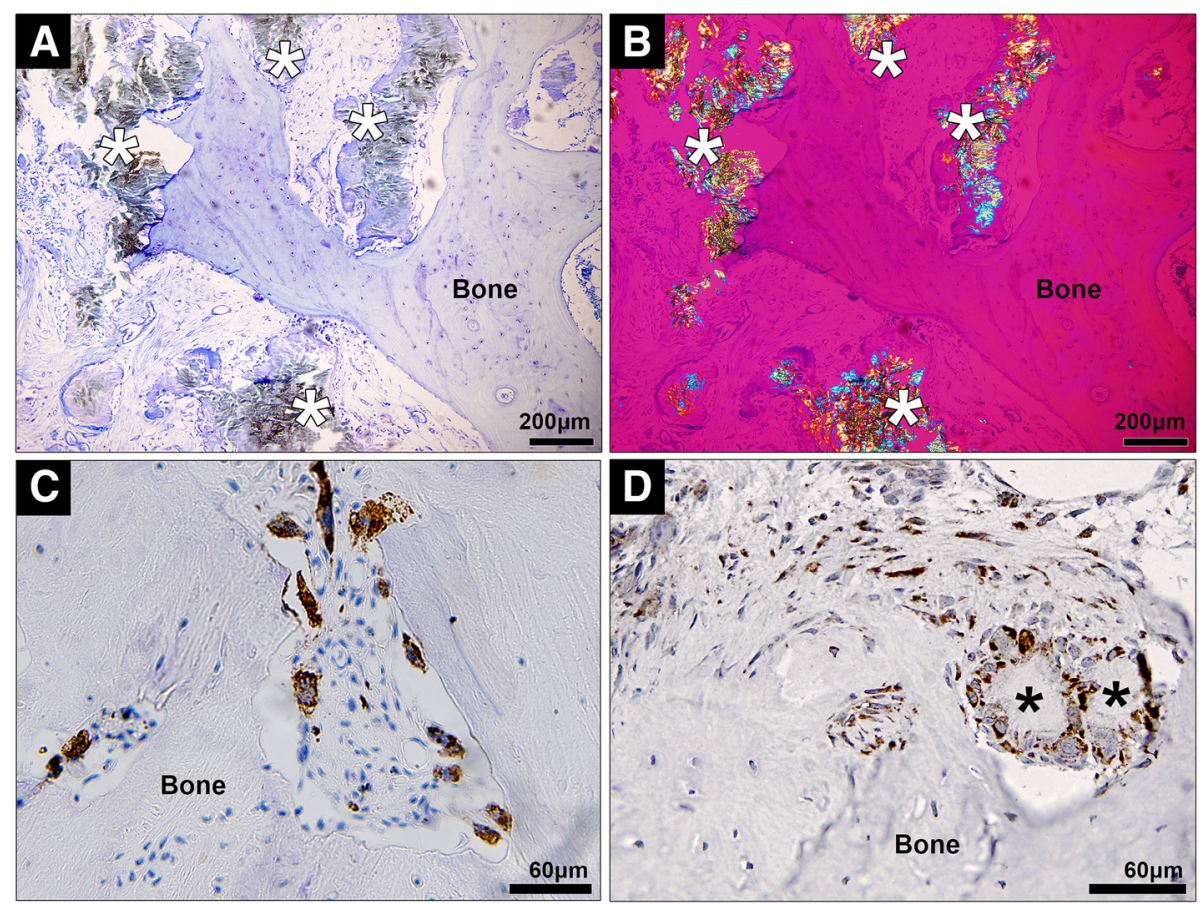

Fig. 6 Histological analysis of human joint tissue affected by tophaceous gout. a,b Representative photomicrographs of joint samples affected by tophaceous gout, showing both MSU crystals (indicated by asterisks) and associated inflammatory tissue in close proximity to bone (a, toluidine blue staining viewed using light microscopy; $\mathbf{b}$, viewed using polarizing light microscopy with a red compensator). Immunohistochemistry staining for $\mathbf{c} \mathrm{CD}^{+} 8^{+}$cells (macrophages) and $\mathbf{d}$ COX-2 expression in human joint tissue affected by tophaceous gout

gout. The addition of conditioned medium from macrophages cultured with MSU crystals to MLO-Y4 cells led to upregulated expression of genes involved in osteocyte communication (connexin 43 and E11), indicating that the cells may be responding to the external stress [21, 22]. In addition, cytokines and factors known to increase osteoclastogenesis and bone resorption were also upregulated in the MLO-Y4 cell cultures, including TNF- $\alpha$ [23], IL-6 [24], IL-11 [25], and RANKL [26]. COX-2 gene expression was also upregulated in response to MSU crystal-stimulated conditioned medium. Induction of COX-2 leads to the synthesis of prostaglandins, such as $\mathrm{PGE}_{2}$. In the same experiments, $\mathrm{PGE}_{2}$ levels were significantly increased in response to MSU crystal-stimulated conditioned medium. $\mathrm{PGE}_{2}$ has important effects on bone metabolism and can promote both bone resorption and formation [27, 28]. IL- 6 and IL-11 are also known to have roles in promoting bone formation under conditions of increased bone turnover [29, 30]. Of note, pathological new bone formation is observed in patients with advanced gout and is more frequently observed in joints with tophi [31]. Thus, osteocytes exposed to MSU crystal-induced inflammation may contribute to both aspects of disordered bone remodeling in gout: pathological bone formation and increased bone resorption.

The addition of MSU crystals to RAW264.7 cells in vitro led to increased secretion of TNF- $\alpha$ and $\mathrm{PGE}_{2}$ and, although TNF- $\alpha$ was secreted at higher concentrations, the downstream proinflammatory response evoked in MLO-Y4 osteocytes is unlikely to be dependent on TNF- $\alpha$ since neutralization of TNF- $\alpha$ had no major effect on the induced inflammatory response. In contrast, inhibition of COX-2 activity in MLO-Y4 cells did suppress the induced expression of IL-6, IL-11, RANKL, and $\mathrm{PGE}_{2}$. The molecular mechanism by which COX-2 inhibition blocked MLO-Y4 cell expression of cytokines and inflammatory mediators in response to MSU crystalinduced inflammation was not further investigated in this study. However, other studies using stromal cells, such as fibroblasts and epithelial cells, have shown a link between $\mathrm{COX}-2$ activation, $\mathrm{PGE}_{2}$ release, and the subsequent expression of IL-6 in response to inflammatory stimuli [32, 33]. In these studies, COX-2 inhibition decreased downstream IL- 6 gene and protein expression $[32,33]$ by inhibiting $\mathrm{PGE}_{2}$ activation of NF- $\mathrm{\kappa} \beta$ and $\mathrm{C} / \mathrm{EBP} \beta$ transcription factors [33]. Other research has demonstrated that addition of exogenous $\mathrm{PGE}_{2}$ directly induces IL- 6 expression in osteoblasts and fibroblasts [24, 34]. In the current study, COX-2 inhibition did not significantly change MLO-Y4 gene expression of COX-2 but did significantly reduce MLO-Y4 production of $\mathrm{PGE}_{2}$, indicating that increased COX-2 activity is important for the downstream inflammatory response. In tophaceous joint samples, COX-2 protein expression was observed near sites of bone 
erosion. These results suggest that upregulated COX-2 activity and $\mathrm{PGE}_{2}$ production at sites affected by tophaceous gout may be important for driving the shift in osteocyte phenotype towards a proinflammatory and proresorptive state in response to MSU crystal-induced inflammation. COX-2 has also been implicated in bone resorption in other forms of inflammatory arthritis. In animal models of rheumatoid arthritis, COX-2 inhibition can reduce inflammatory bone erosion [35, 36]. For current gout management, COX-2 inhibitors are used as anti-inflammatory agents for treatment and prevention of gout flares. Our results raise the possibility that COX-2 inhibition may also inhibit the cellular processes contributing to pathological bone remodeling in tophaceous gout.

IL-1 $\beta$ plays a key role in initiation of the acute gout flare $[37,38]$. In our in-vitro model of MSU crystal-induced inflammation by macrophages, IL- $1 \beta$ secretion was not upregulated in RAW264.7 macrophage cells cultured with MSU crystals. This is consistent with previous in-vitro studies where MSU crystals alone did not induce IL-1 $\beta$ release in human or murine macrophages without additional priming of cells with either lipopolysaccharide or phorbol 12-myristate 13-acetate [39, 40]. Activation of the inflammasome and release of IL-1 $\beta$ is critical for initiating the intense acute inflammatory response in the gout flare [37]. However, tophi are not typically acutely inflamed. Therefore, we believe that the indirect experiments using macrophage conditioned medium represent a relevant in-vitro model to examine how interactions between MSU crystals and macrophages affect osteocyte-regulated bone remodeling in tophaceous gout.

\section{Conclusions}

In summary, MSU crystals directly reduce osteocyte viability but have no direct effects on osteocyte gene expression. In contrast, interactions between MSU crystals and macrophages indirectly promote osteocyte expression of proinflammatory mediators and factors involved in bone remodeling, particularly proresorptive factors; these effects can be suppressed with COX-2 inhibition in osteocytes. These interactions may contribute to disordered bone remodeling in tophaceous gout.

\section{Additional files}

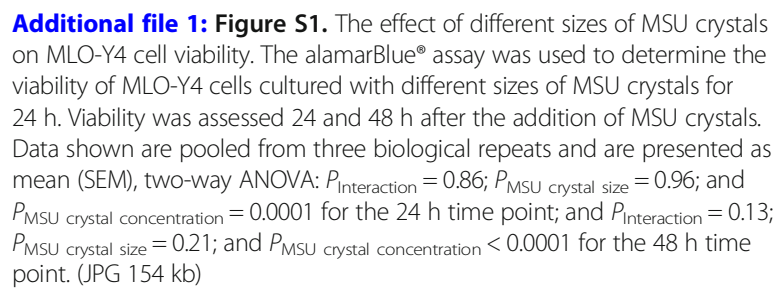

Additional file 2: Figure S2. Indirect effects of MSU crystal-stimulated RAW264.7 macrophage conditioned medium on MLO-Y4 cell viability. RAW264.7 macrophages were cultured with or without $0.5 \mathrm{mg} / \mathrm{mL}$ MSU crystals for $24 \mathrm{~h}$ for preparation of MSU crystal-stimulated conditioned medium and control conditioned medium, respectively. Conditioned medium preparations were added to MLO-Y4 cells at different concentrations $\left(5 \%, 20 \%\right.$, and $40 \%$ final concentration in a well) for $24 \mathrm{~h}$. The alamarBlue ${ }^{\oplus}$ assay was used to determine MLO-Y4 cell viability $24 \mathrm{~h}$ and $48 \mathrm{~h}$ after the addition of conditioned medium. Data shown are pooled from three biological repeats and are presented as mean (SEM), two-way ANOVA: $P_{\text {Interaction }}=0.16 ; P_{\text {Time }}=0.74$; and $P_{\text {Conditioned media concentration }}=0.17$. (JPG $152 \mathrm{~kb}$ )

Additional file 3: Figure S3. RAW264.7 macrophage expression of TNF- $a$ and $\mathrm{PGE}_{2}$ in response to MSU crystals. RAW264.7 macrophages were cultured with or without $0.5 \mathrm{mg} / \mathrm{mL}$ MSU crystals for $24 \mathrm{~h}$ for preparation of MSU crystal-stimulated conditioned medium and control conditioned medium, respectively. The concentration of TNF-a, PGE2, IL-1ß, IL-6, RANKL, and OPG in conditioned medium samples were measured by ELISA. IL-6 and RANKL were undetected in all samples. Data shown are pooled from three biological repeats and are presented as mean (SEM), two-tailed paired $t$ test as indicated between groups. (JPG $156 \mathrm{~kb}$ )

Additional file 4: Figure S4. The effect of neutralizing TNF-a on MLO-Y4 cell inflammation induced by MSU crystal-stimulated RAW264.7 macrophages. RAW264.7 macrophages were cultured with or without $0.5 \mathrm{mg} / \mathrm{mL}$ MSU crystals for $24 \mathrm{~h}$ for preparation of MSU crystal-stimulated conditioned medium and control conditioned medium, respectively. Conditioned medium and either $5 \mu \mathrm{g} / \mathrm{mL}$ neutralizing TNF-a antibody or $5 \mu \mathrm{g} / \mathrm{mL} \operatorname{lgG}$ isotype control were added to MLO-Y4 cells for $24 \mathrm{~h}$ and MLO-Y4 cells were then harvested and mRNA extracted for analysis of gene expression by real-time PCR. Data shown are pooled from four biological repeats and are presented as mean (SEM), one-way ANOVA with post-hoc Sidak's test between groups as indicated. NS no significant difference. (JPG $203 \mathrm{~kb})$

\section{Abbreviations}

3D: Three-dimensional; ANOVA: Analysis of variance; BCP: Basic calcium phosphate; COX-2: Cyclooxygenase-2; CPPD: Calcium pyrophosphate dehydrate; ELISA: Enzyme-linked immunosorbent assay; FBS: Fetal bovine serum; IL: Interleukin; MSU: Monosodium urate; NF-K $\beta$ : Nuclear factor kappa-B; OPG: Osteoprotegerin; PCR: Polymerase chain reaction; $\mathrm{PGE}_{2}$ : Prostaglandin $\mathrm{E}_{2}$; RANKL: Receptor activator of nuclear factor kappa-B ligand; TNF: Tumor necrosis factor

\section{Acknowledgments}

The authors wish to acknowledge Peter Riordan and Satya Amirapu from the Department of Anatomy and Medical Imaging, University of Auckland, New Zealand, for assistance with collection of cadaveric specimens and histological processing, respectively.

\section{Funding}

This study was funded by the Auckland Medical Research Foundation (Project grant 9101/3709989) and The University of Auckland (FRDF grant 9101/3704255). AC was funded by a Royal Society of New Zealand Rutherford Foundation Post-Doctoral Research Fellowship (grant 9101/3709428).

\section{Availability of data and materials}

The datasets used and/or analyzed during the current study are available from the corresponding author on reasonable request.

\section{Authors' contributions}

ND (the guarantor) accepts full responsibility for the work and the conduct of the study, had access to the data, and controlled the decision to publish. Design of study protocol: AC, DM, DN, GM, SM, JC, and ND. Acquisition of study data: AC, BP, KEC, and MLT. Data analysis: AC and ND. Interpretation of data: AC, DN, and ND. Drafting of manuscript: AC and ND. Final approval of manuscript: all authors.

\section{Ethics approval and consent to participate}

Human sample collection was approved by the Northern Regional Ethics Committee and all participants provided written informed consent. Protocols 
involving animals were approved by the University of Auckland Animal Ethics Committee. Use of human cadaveric tissue was in accordance with the New Zealand Human Tissue Act 2008.

\section{Consent for publication}

Not applicable.

\section{Competing interests}

ND has received consulting fees, speaker fees, or grants from Takeda, Teijin, Menarini, Pfizer, Ardea, AstraZeneca, Cymabay, Amgen, Abbvie, and Horizon outside the submitted work. The remaining authors declare that they have no competing interests.

\section{Publisher's Note}

Springer Nature remains neutral with regard to jurisdictional claims in published maps and institutional affiliations.

\section{Author details}

'Department of Medicine, Bone \& Joint Research Group, University of Auckland, Auckland, New Zealand. ²Department of Rheumatology, Mater Misericordiae University Hospital, Dublin, Ireland. ${ }^{3}$ Department of Anatomy and Medical Imaging, University of Auckland, Auckland, New Zealand. ${ }^{4}$ Department of Medicine, Faculty of Medical and Health Sciences, University of Auckland, 85 Park Rd, Grafton, Auckland, New Zealand.

\section{Received: 15 March 2018 Accepted: 16 August 2018}

\section{Published online: 10 September 2018}

\section{References}

1. Dalbeth N, Clark B, Gregory K, Gamble G, Sheehan T, Doyle A, McQueen FM. Mechanisms of bone erosion in gout: a quantitative analysis using plain radiography and computed tomography. Ann Rheum Dis. 2008:8:1290-5.

2. Dalbeth N, Pool B, Gamble GD, Smith T, Callon KE, McQueen FM, Cornish J. Cellular characterization of the gouty tophus: a quantitative analysis. Arthritis Rheum. 2010;62(5):1549-56.

3. Sapsford M, Gamble GD, Aati O, Knight J, Horne A, Doyle AJ, Dalbeth N. Relationship of bone erosion with the urate and soft tissue components of the tophus in gout: a dual energy computed tomography study. Rheumatology. 2016:1:129-33.

4. Dalbeth N, Smith T, Nicolson B, Clark B, Callon K, Naot D, Haskard DO, McQueen FM, Reid IR, Cornish J. Enhanced osteoclastogenesis in patients with tophaceous gout: urate crystals promote osteoclast development through interactions with stromal cells. Arthritis Rheum. 2008;58(6):1854-65.

5. Lee SJ, Nam Kl, Jin HM, Cho YN, Lee SE, Kim TJ, Lee SS, Kee SJ, Lee KB, Kim $\mathrm{N}$, et al. Bone destruction by receptor activator of nuclear factor kappaB ligand-expressing T cells in chronic gouty arthritis. Arthritis Res Ther. 2011; 13(5):R164.

6. Chhana A, Callon KE, Pool B, Naot D, Watson M, Gamble GD, McQueen FM, Cornish J, Dalbeth N. Monosodium urate monohydrate crystals inhibit osteoblast viability and function: implications for development of bone erosion in gout. Ann Rheum Dis. 2011;9:1684-91.

7. Nakashima T, Hayashi M, Fukunaga T, Kurata K, Oh-hora M, Feng JQ, Bonewald LF, Kodama T, Wutz A, Wagner EF, et al. Evidence for osteocyte regulation of bone homeostasis through RANKL expression. Nat Med. 2011; 17(10):1231-4

8. Kramer I, Halleux C, Keller H, Pegurri M, Gooi JH, Weber PB, Feng JQ, Bonewald LF, Kneissel M. Osteocyte Wnt/beta-catenin signaling is required for normal bone homeostasis. Mol Cell Biol. 2010;30(12):3071-85.

9. Bonewald LF. The amazing osteocyte. J Bone Miner Res. 2011;26(2):229-38.

10. Chhana A, Aati O, Gamble GD, Callon KE, Doyle AJ, Roger M, McQueen FM, Horne A, Reid IR, Cornish J, et al. Path analysis identifies receptor activator of nuclear factor-kappaB ligand, osteoprotegerin, and sclerostin as potential mediators of the tophus-bone erosion relationship in gout. J Rheumatol. 2016;43(2):445-9.

11. Kato Y, Windle JJ, Koop BA, Mundy GR, Bonewald LF. Establishment of an osteocyte-like cell line, MLO-Y4. J Bone Miner Res. 1997;12(12):2014-23.

12. Yellowley CE, Li Z, Zhou Z, Jacobs CR, Donahue HJ. Functional gap junctions between osteocytic and osteoblastic cells. J Bone Miner Res. 2000;15(2):209-17.
13. Stern AR, Stern MM, Van Dyke ME, Jahn K, Prideaux M, Bonewald LF. Isolation and culture of primary osteocytes from the long bones of skeletally mature and aged mice. Biotechniques. 2012;52(6):361-73.

14. Matthews BG, Naot D, Callon KE, Musson DS, Locklin R, Hulley PA, Grey A, Cornish J. Enhanced osteoblastogenesis in three-dimensional collagen gels. Bonekey Rep. 2014;3:560.

15. Denko CW, Whitehouse MW. Experimental inflammation induced by naturally occurring microcrystalline calcium salts. J Rheumatol. 1976;3(1):54-62.

16. Evans RW, Cheung HS, McCarty DJ. Cultured human monocytes and fibroblasts solubilize calcium phosphate crystals. Calcif Tissue Int. 1984;1: 645-50.

17. Chhana A, Callon KE, Dray M, Pool B, Naot D, Gamble GD, Coleman B, McCarthy G, McQueen FM, Cornish J, et al. Interactions between tenocytes and monosodium urate monohydrate crystals: implications for tendon involvement in gout. Ann Rheum Dis. 2014;73(9):1737-41.

18. Tatsumi S, Ishii K, Amizuka N, Li M, Kobayashi T, Kohno K, Ito M, Takeshita S, Ikeda K. Targeted ablation of osteocytes induces osteoporosis with defective mechanotransduction. Cell Metab. 2007;5(6):464-75.

19. Verborgt O, Gibson GJ, Schaffler MB. Loss of osteocyte integrity in association with microdamage and bone remodeling after fatigue in vivo. J Bone Miner Res. 2000;15(1):60-7.

20. Kennedy OD, Herman BC, Laudier DM, Majeska RJ, Sun HB, Schaffler MB. Activation of resorption in fatigue-loaded bone involves both apoptosis and active pro-osteoclastogenic signaling by distinct osteocyte populations. Bone. 2012;50(5):1115-22.

21. Zhang K, Barragan-Adjemian C, Ye L, Kotha S, Dallas M, Lu Y, Zhao S, Harris M, Harris SE, Feng JQ, et al. E11/gp38 selective expression in osteocytes: regulation by mechanical strain and role in dendrite elongation. Mol Cell Biol. 2006;26(12):4539-52.

22. Cherian PP, Siller-Jackson AJ, Gu S, Wang X, Bonewald LF, Sprague E, Jiang JX. Mechanical strain opens connexin 43 hemichannels in osteocytes: a novel mechanism for the release of prostaglandin. Mol Biol Cell. 2005;16(7): 3100-6.

23. Bertolini DR, Nedwin GE, Bringman TS, Smith DD, Mundy GR. Stimulation of bone resorption and inhibition of bone formation in vitro by human tumour necrosis factors. Nature. 1986:319(6053):516-8.

24. Ishimi Y, Miyaura C, Jin CH, Akatsu T, Abe E, Nakamura Y, Yamaguchi A, Yoshiki S, Matsuda T, Hirano T. IL-6 is produced by osteoblasts and induces bone resorption. J Immunol. 1990;145(10):3297-303.

25. Sims NA, Jenkins BJ, Nakamura A, Quinn JMW, Li R, Gillespie MT, Ernst M, Robb L, Martin TJ. Interleukin-11 receptor signaling is required for normal bone remodeling. J Bone Miner Res. 2005;20(7):1093-102.

26. Kong YY, Yoshida H, Sarosi I, Tan HL, Timms E, Capparelli C, Morony S, Oliveira-dos-Santos AJ, Van G, Itie A, et al. OPGL is a key regulator of osteoclastogenesis, lymphocyte development and lymph-node organogenesis. Nature. 1999;397(6717):315-23.

27. Klein DC, Raisz LG. Prostaglandins: stimulation of bone resorption in tissue culture. Endocrinology. 1970;86(6):1436-40.

28. Nefussi JR, Baron R. PGE2 stimulates both resorption and formation of bone in vitro: differential responses of the periosteum and the endosteum in fetal rat long bone cultures. Anat Rec. 1985;211(1):9-16.

29. Sims NA, Jenkins BJ, Quinn JMW, Nakamura A, Glatt M, Gillespie MT, Ernst M, Martin TJ. Glycoprotein 130 regulates bone turnover and bone size by distinct downstream signaling pathways. J Clin Invest. 2004;113(3):379-89.

30. Takeuchi $Y$, Watanabe S, Ishii G, Takeda S, Nakayama K, Fukumoto S, Kaneta $Y$, Inoue D, Matsumoto T, Harigaya K, et al. Interleukin-11 as a stimulatory factor for bone formation prevents bone loss with advancing age in mice. J Biol Chem. 2002;277(50):49011-8.

31. Dalbeth N, Milligan A, Doyle AJ, Clark B, McQueen FM. Characterization of new bone formation in gout: a quantitative site-by-site analysis using plain radiography and computed tomography. Arthritis Res Ther. 2012;14(4):R165.

32. Bukata SV, Gelinas J, Wei X, Rosier RN, Puzas JE, Zhang X, Schwarz EM, Song $X R$, Griswold DE, O'Keefe RJ. PGE2 and IL-6 production by fibroblasts in response to titanium wear debris particles is mediated through a cox-2 dependent pathway. J Orthop Res. 2004;22(1):6-12.

33. Zhao Y, Usatyuk PV, Gorshkova IA, He D, Wang T, Moreno-Vinasco L, Geyh AS, Breysse PN, Samet JM, Spannhake EW, et al. Regulation of COX-2 expression and IL-6 release by particulate matter in airway epithelial cells. Am J Respir Cell Mol Biol. 2009;40(1):19-30.

34. Inoue H, Takamori M, Shimoyama Y, Ishibashi H, Yamamoto S, Koshihara Y. Regulation by PGE(2) of the production of interleukin-6, macrophage colony 
stimulating factor, and vascular endothelial growth factor in human synovial fibroblasts. Br J Pharmacol. 2002;136(2):287-95.

35. Noguchi M, Kimoto A, Sasamata M, Miyata K. Micro-CT imaging analysis for the effect of celecoxib, a cyclooxygenase-2 inhibitor, on inflammatory bone destruction in adjuvant arthritis rats. J Bone Miner Metab. 2008;26(5):461-8.

36. Katagiri M, Ogasawara T, Hoshi K, Chikazu D, Kimoto A, Noguchi M,

Sasamata M, Harada S, Akama H, Tazaki H, et al. Suppression of adjuvantinduced arthritic bone destruction by cyclooxygenase-2 selective agents with and without inhibitory potency against carbonic anhydrase II. J Bone Miner Res. 2006;21(2):219-27.

37. Martinon F, Petrilli V, Mayor A, Tardivel A, Tschopp J. Gout-associated uric acid crystals activate the NALP3 inflammasome. Nature. 2006;440(7081):237-41.

38. Chen C-J, Shi Y, Hearn A, Fitzgerald K, Golenbock D, Reed G, Akira S, Rock $\mathrm{KL}$. MyD88-dependent IL-1 receptor signaling is essential for gouty inflammation stimulated by monosodium urate crystals. J Clin Invest. 2006; 116(8):2262-71.

39. Joosten LA, Netea MG, Mylona E, Koenders MI, Malireddi RK, Oosting M, Stienstra R, van de Veerdonk FL, Stalenhoef AF, Giamarellos-Bourboulis EJ, et al. Engagement of fatty acids with toll-like receptor 2 drives interleukin1 beta production via the ASC/caspase 1 pathway in monosodium urate monohydrate crystal-induced gouty arthritis. Arthritis Rheum. 2010;62(11): 3237-48.

40. Giamarellos-Bourboulis EJ, Mouktaroudi M, Bodar E, van der Ven J, Kullberg BJ, Netea MG, van der Meer JW. Crystals of monosodium urate monohydrate enhance lipopolysaccharide-induced release of interleukin 1 beta by mononuclear cells through a caspase 1-mediated process. Ann Rheum Dis. 2009;68(2):273-8.

Ready to submit your research? Choose BMC and benefit from:

- fast, convenient online submission

- thorough peer review by experienced researchers in your field

- rapid publication on acceptance

- support for research data, including large and complex data types

- gold Open Access which fosters wider collaboration and increased citations

- maximum visibility for your research: over $100 \mathrm{M}$ website views per year

At $\mathrm{BMC}$, research is always in progress.

Learn more biomedcentral.com/submissions 